\section{Complete Sequences of the $S$-genes, Sd- and Sh-RNase cDNA in Apple}

\author{
Kentaro Kitahara \\ The United Graduate School of Agricultural Science, Gifu University, Gifu \\ 501-1193, Japan
}

Junichi Soejima

Apple Research Center, National Institute of Fruit Tree Science, Morioka 0200123, Japan

\section{Hiromitsu Komatsu}

Nagano Fruit Tree Experiment Station, Nagano 382-0072, Japan

Hirokazu Fukui

Laboratory of Horticulture, Faculty of Agriculture, Gifu University, Gifu 5011193, Japan

\section{Shogo Matsumoto ${ }^{1}$}

Department of Biology, Faculty of Education, Gifu University, Gifu 501-1193, Japan

Additional index words. Malus $\times$ domestica, $S$-allele, PCR, pistil, leaf

\begin{abstract}
The $S$-locus genes in the pistil (S-RNases) were cloned from the apple (Malus $\times$ domestica Borkh.) cultivar Akane ( $S$-genotype $S d S h$ from pollination analysis). The Sd- and Sh-RNase corresponded to S7- and S24-RNase, which have been cloned from 'Idared' and 'Braeburn', respectively. Sh-RNase was very similar to Sf- and Sg-RNases at the deduced amino acid-sequence levels $(93 \%)$. We developed an $S$-allele specific polymerase chain reaction (PCR)-restriction fragment length polymorphism (RFLP) analysis method for distinguishing the $S h$ from $S f$ and $S g$, and the $S h$-alleles of 'Akane', 'Touhoku 2', 'Vista Bella', and 'Worcester Pearmain' were identified. We also identified the $S$-allele genotypes of 16 apple cultivars.
\end{abstract}

Gametophytic self-incompatibility in the apple is controlled by a single, multiallelic locus, the $S$-locus. In this system, pollen tube growth is inhibited when pollen shares the same $S$-allele with the pistil on which the pollen landed.

The $S$-locus genes in the pistil have been cloned from apple cultivars. As the $S$-genes in the pistil encode ribonuclease, they are called S-RNases. Sc-, Sf-, and Sg-RNases have been cloned from apple cultivars in Japan (Kitahara et al., 1999; Sassa et al., 1996), and S2-, S3-, S5-, S7-, S9-, S24-, S26-, and S27-RNases from apple cultivars in Europe (Broothaerts et al., 1995; Janssens et al., 1995; Verdoodt et al., 1998). Sc- and S9-RNase are identical at the deduced amino acid sequence level.

Komori et al. (1998) established $\mathrm{Sa}$-, $\mathrm{Sb}$-, $S c-, S d-, S e$-, and $S f$-allele genotypes by polli-

Received for publication 16 Sept. 1999, Accepted for publication 21 Dec. 1999. We thank Mio Mishima for her assistance. This research was supported by a Grant-in-Aid for Scientific Research from the Ministry of Education, Science, Sports and Culture of Japan (No. 11660025). The cost of publishing this paper was defrayed in part by the payment of page charges. Under postal regulations, this paper therefore must be hereby marked advertisement solely to indicate this fact.

${ }^{1}$ To whom reprint requests should be addressed. E-mail address: shmatsum@cc.gifu-u.ac.jp nation and progeny analysis of apple cultivars in Japan. Using the molecular method of $S$ allele identification based on polymerase chain reaction(PCR)-restricted fragment length polymorphism (RFLP) analysis, developed by Janssens et al. (1995) and modified by Sakurai et al. (1997) and Matsumoto et al. (1999a, 1999b), to analyze apple cultivars in Japan, it was confirmed that $S a, S b$, and $S d$ correspond to $S 2, S 3$, and $S 7$, respectively. However, $S e$, $S f$, and $S g$ did not correspond to $S 5, S 24, S 26$, or $S 27$.

Previously, the $S$-allele genotype of 'Akane' was identified as $S 7 S$ (unknown) using the PCR-RFLP method (Sakurai et al., 1997). S7allele corresponds to the $S d$-allele, and the $S$ allele genotype of 'Akane' was identified as $S d S h$ by pollination and progeny analysis (S. Komori, personal communication). In this study, the cDNA sequences encoding Sd- and Sh-RNase were determined. We also identivars by $S$-allele-specific PCR-RFLP analyses.

\section{Materials and Methods}

Plant material. Most of the plants used in this study were from collections at the Apple Research Center of the National Institute of Fruit Tree Science, Japan. 'Akibae' and 'Chouka 8' were obtained from the Nagano Fruit Tree Experiment Station, Japan. 'Akane' fied the $S$-allele genotypes of 16 apple culti- flowers were collected at the popcorn stage, and the pistils were removed and immediately frozen in liquid nitrogen and stored at $-80{ }^{\circ} \mathrm{C}$. Pistils of other cultivars were obtained in the same way. Young leaves were collected and stored at $-80{ }^{\circ} \mathrm{C}$ until used.

Sh-RNase cDNA cloning. Total RNAs of the mature pistils were extracted essentially as described by Chang et al. (1993). Reverse transcription (RT) was performed in a total volume of $20 \mu \mathrm{L}$ containing $1 \mu \mathrm{L}(\approx 1.0 \mu \mathrm{g})$ of RNA, $0.125 \mu \mathrm{M}$ Oligo dT-Adaptor Primer (Takara Shuzo Co., Kusatsu, Shiga, Japan), 0.25 U AMV Reverse Transcriptase XL (Takara Shuzo Co.), 20 U RNase Inhibitor (Takara Shuzo Co.), $1 \mathrm{~mm}$ dNTPs, $5 \mathrm{~mm}$ $\mathrm{MgCL}_{2}$, and $1 \times$ RNA PCR buffer (10 mM Tris- $\mathrm{HCl} \mathrm{pH} 8.3,50 \mathrm{~mm} \mathrm{KCl}$ ). The analysis was programmed in a thermal cycler (GeneAmp 2400 apparatus; Perkin-Elmer Co., Urayasu, Chiba, Japan) and conducted under the following conditions: $60 \mathrm{~min}$ at 42 ${ }^{\circ} \mathrm{C}, 5 \mathrm{~min}$ at $99{ }^{\circ} \mathrm{C}$, and cooling to $4{ }^{\circ} \mathrm{C}$. A PCR was carried out in a total volume of 100 $\mu \mathrm{L}$ containing $20 \mu \mathrm{L}$ of the RT reaction mixture; $0.2 \mu \mathrm{M}$ OWB134 primer (Broothaerts et al., 1995), $0.2 \mu \mathrm{M}$ M13 Primer M4 (Takara Shuzo Co.), which was complementary to the adaptor region of the OligodT-Adaptor primer; $2.5 \mathrm{~mm} \mathrm{MgCl}_{2}, 1 \times \mathrm{RNA}$ PCR buffer; and 2.5 U Taq DNA polymerase (TaKaRa $\mathrm{Taq}^{\mathrm{TM}}$; Takara Shuzo Co.). The amplification program consisted of $2 \mathrm{~min}$ at $94^{\circ} \mathrm{C}$ for initial denaturation, 45 cycles of $30 \mathrm{~s}$ at $94{ }^{\circ} \mathrm{C}, 30 \mathrm{~s}$ at $50{ }^{\circ} \mathrm{C}, 1.5 \mathrm{~min}$ at $72{ }^{\circ} \mathrm{C}$, and a final extension of $7 \mathrm{~min}$ at $72^{\circ} \mathrm{C}$.

The cDNAs obtained were excised from a $1.0 \%(\mathrm{w} / \mathrm{v})$ agarose gel in TAE (40 mM Trisacetate, 1 mM EDTA pH 8.0), purified by the Geneclean kit (BIO 101 Co., Calif.) and subcloned into a pCRII cloning vector with the TA cloning kits (Invitrogen, Co., Hongo bunkyo-ku, Tokyo). The nucleotide sequences of three clones named Sh-1, -2 , and -3 were determined by dideoxy chain termination on an ABI PRISM ${ }^{\mathrm{TM}} 377$ DNA sequencer (Perkin-Elmer, Co.) using dRhodamine Terminator Cycle Sequencing Kits (Perkin-Elmer Co.).

Sd-RNase cDNA cloning. OWB 126 primer (Janssens et al., 1995) was used as the gene-specific primer for rapid amplification of cDNA 3' ends (3'RACE) (Frohman et al., 1988). A PCR was carried out in a total volume of $100 \mu \mathrm{L}$ containing $20 \mu \mathrm{L}$ of the RT reaction mixture, $0.2 \mu \mathrm{M}$ OWB 126 primer, $0.2 \mu \mathrm{M}$ M13 Primer M4 (Takara Shuzo Co.), $2.5 \mathrm{~mm} \mathrm{MgCl}_{2}, 1 \times \mathrm{RNA}$ PCR buffer, and 2.5 U Taq DNA polymerase (TaKaRa Taq ${ }^{\mathrm{TM}}$; Takara Shuzo Co.). The amplification program consisted of $2 \mathrm{~min}$ at $94^{\circ} \mathrm{C}$ for initial denaturation, 45 cycles of $30 \mathrm{~s}$ at $94{ }^{\circ} \mathrm{C}, 30 \mathrm{~s}$ at $52{ }^{\circ} \mathrm{C}, 1.5 \mathrm{~min}$ at $72{ }^{\circ} \mathrm{C}$, and a final extension of $7 \mathrm{~min}$ at $72{ }^{\circ} \mathrm{C}$.

PCR products were separated on a $1.0 \%$ $(\mathrm{w} / \mathrm{v})$ agarose gel in TAE (40 mm Tris-acetate, 1 mm EDTA, $\mathrm{pH}$ 8.0), and bands of ca. $600 \mathrm{bp}$ were purified by the Geneclean Kit (BIO 101 Co.), then subcloned with the pCRII cloning vector. Two cDNA $3^{\prime}$ end clones named Sd-3'-1 and -2 were obtained. 
To obtain the cDNA $5^{\prime}$ ends of the cDNA $3^{\prime}$ end clones, rapid amplification of cDNA $5^{\prime}$ ends ( $5^{\prime}$ RACE) was carried out using a 5'-Full RACE Core Set (Takara Shuzo Co.). First, the reaction mixtures were prepared according to the manufacturer's instructions (Takara Shuzo Co.). These mixtures were for first strand cDNA synthesis by RT using the cDNA $3^{\prime}$ end clone specific 5'-phosphorylated RT-primer, Sd-PF1 (5' P-TCAGTCACCTGGTTA-3'; nucleotides 624-638 in Fig. 2), which is specific for Sd-3'-1 and -2 . The analysis was conducted under the following conditions: $10 \mathrm{~min}$ at $30^{\circ} \mathrm{C}, 60 \mathrm{~min}$ at $50^{\circ} \mathrm{C}$, and $2 \mathrm{~min}$ at $80^{\circ} \mathrm{C}$, followed by cooling to $4{ }^{\circ} \mathrm{C}$.

After the RT reaction, the hybrid RNA of the cDNA first strand was degraded by $\mathrm{RNaseH}$, then the cDNA first strand was selfligated by T4 RNA ligase according to the manufacturer's instructions (Takara Shuzo Co.).

For the first and second PCRs of the selfligated cDNA first strand with Sd-PF1 primer, two sets of the oligonucleotide primers were designed. For the first PCR the primers were Sd-5S1 (5'-AAACATGGCACCTGTGGACA-3'; nucleotides 409-428 in Fig. 2) and Sd5A1 (5'-ACTGAGTTGTCAGATTTCCT-3'; nucleotides 321-340 in Fig. 2). For the second PCR the primers were $\mathrm{Sd}-5 \mathrm{~S} 2$ (5'-ATCCCACAATAATGAACGAC-3'; nucleotides 428447 in Fig. 2) and Sd-5A2 (5'-AGCATCCACGGTTGATTTAC-3'; nucleotides 293-312 in Fig. 2). The reaction mixtures of the first and second PCRs were prepared according to the manufacturer's instructions (Takara Shuzo Co.). The amplification program for the first PCR consisted of $3 \mathrm{~min}$ at $94{ }^{\circ} \mathrm{C}$ for initial denaturation, 25 cycles of $30 \mathrm{~s}$ at $94^{\circ} \mathrm{C}, 30 \mathrm{~s}$ at $55^{\circ} \mathrm{C}, 1.5 \mathrm{~min}$ at $72{ }^{\circ} \mathrm{C}$, and a final extension of $7 \mathrm{~min}$ at $72^{\circ} \mathrm{C}$. The program for the second PCR consisted of 35 cycles of $30 \mathrm{~s}$ at $94{ }^{\circ} \mathrm{C}$, $30 \mathrm{~s}$ at $55^{\circ} \mathrm{C}, 1 \mathrm{~min}$ at $72{ }^{\circ} \mathrm{C}$, and a final extension of $7 \mathrm{~min}$ at $72^{\circ} \mathrm{C}$. After the second PCR, the PCR products were separated as described above, and they were then subcloned with the pCRII-cloning vector. Two cDNA clones named Sd-5'-1 and -2, corresponding to $\mathrm{Sd}-3^{\prime}$ clones, were obtained. The nucleotide sequences of $\mathrm{Sd}-3^{\prime}$ and $\mathrm{Sd}-5^{\prime}$ clones were determined as described above.

$S$-allele specific PCR analysis of DNA. Total DNA from leaves of individual plants was isolated as described by Thomas et al. (1993). S2-, S3-, S5-, S7-, S9-, Sf-, and Sgallele-specific PCR amplification and digestion were carried out essentially as described by Matsumoto et al. (1999a, 1999b). For Sh-allele identification, PCR was conducted using sense (5'-ACGATCATGAAGGCTTCTGGCG-3'; Sf-sense 3) and antisense (5'TTGGTGGGGCAGAAATTCC-3’; Sfantisense 2 from Matsumoto et al., 1999a) primers, with the total DNA of each cultivar being expected to possess the $S f$ - or $S g$ - or $S h$ allele. Each $35-\mu \mathrm{L}$ PCR mixture contained 1.0 $\mu \mathrm{M}$ of each primer, $200 \mu \mathrm{M}$ deoxynucleotides, $10 \mathrm{~mm}$ Tris- $\mathrm{HCl}$ (pH 8.3), $50 \mathrm{~mm} \mathrm{KCl}, 1.5 \mathrm{~mm}$ $\mathrm{MgCl}_{2}, 0.001 \%$ (w/v) gelatin, $2.5 \mathrm{U}$ Taq polymerase, and $50 \mathrm{ng}$ template DNA. The analy- sis was programmed in a thermal cycler (GeneAmp 2400 apparatus; Perkin-ElmerCo.) and conducted under the following conditions: $3 \mathrm{~min}$ at $94{ }^{\circ} \mathrm{C}$ for preheating, $1 \mathrm{~min}$ at $94{ }^{\circ} \mathrm{C}, 1 \mathrm{~min}$ at $56^{\circ} \mathrm{C}$, and $1 \mathrm{~min}$ at $72^{\circ} \mathrm{C}$ for 30 cycles, followed by an extension for $10 \mathrm{~min}$ at $72{ }^{\circ} \mathrm{C}$. After PCR, the amplified fragments were digested by SnaBI. The amplified and digested fragments were separated on a $4 \%$ polyacrylamide gel in TAE (40 mM Trisacetate, $1 \mathrm{~mm}$ EDTA, $\mathrm{pH} 8.0$ ) at 50-70 V for $1-1.5 \mathrm{~h}$.

\section{Results and Discussion}

The OWB134 primer anneals to a conserved region in all known S-RNases, and its $3^{\prime}$-nucleotide triplet corresponds with translation initiation codon ATG (Verdoodt et al., 1998). An RT-PCR product of $\approx 840 \mathrm{bp}$ from 'Akane' apple was subcloned for further analysis.

We sequenced three independent clones; all cDNA inserts represented an $S$-locus gene (Fig. 1). The nucleotide sequences of the clones termed Sh-1, -2 , and -3 were matched with those of the S24-RNase from 'Braeburn' (Verdoodt et al., 1998) except for two nucleotides in $3^{\prime}$ untranslated region (nucleotide positions 828 from $\mathrm{T}$ to $\mathrm{C}$, and 832 from $\mathrm{T}$ to $\mathrm{A}$ in Fig. 1). The protein sequences of Sh- and S24-RNase are identical, as are those of Scand S9-RNase. We could not obtain the cDNA clone corresponding to Sd-RNase by using the OWB134 primer, because the primer might not anneal to the conserved region of the SdRNase. Because the Sd-RNase corresponds to S7-RNase, the Sd-RNase cDNA 3' end clone should be obtained by $3^{\prime}$ RACE methods with the primer OWB 126 designed from S7-RNase by Janssens et al. (1995).

We obtained two $3^{\prime}$ end cDNA clones termed Sd-3'-1 and -2 . The two clones were identical except for the site of a poly (A) addition (nucleotide position 798 for Sd-3'-1 and 840 for Sd-3'-2 in Fig. 2). The nucleotide sequences of Sd-3' clones were matched with those of the S7-RNase from 'Idared' except for the one nucleotide at nucleotide position 540 from A to G, and the site of a poly (A) addition (nucleotide position 780 for S7-RNase cDNA in Fig. 2). This difference represented in the third letter of triplet codon (GGA for S7RNase and GGG for Sd-3'), and both of the codons representing one amino acid, glycine. Two 5' end cDNA clones, designated Sd-5'-1 and -2 corresponding to the $\mathrm{Sd}-3^{\prime}$ clones were then obtained by $5^{\prime}$ RACE method. The putative initiation codon ATG at position 67-69 is preceded by a stop codon TAA at position 5557 in-frame, and the sequence surrounding the first ATG codon (ATTCAATG) was well conserved in the cDNAs of the apple $S$-genes. The nucleotide sequence of $\mathrm{Sd}-5^{\prime}$ was identical to that of the S7-RNase from 'Idared' except for the $5^{\prime}$-end of the untranslated region and the coding region encoding the first 49 amino acids (nucleotides 1-212 in Fig. 2), which are uncloned in the cDNA clone of S7-RNase (Fig. 2). From these results, the protein sequences of Sd- and S7-RNase seem to be identical. Although Sakurai et al. (1997) identified the $S$-allele genotype of 'Akane' as $S 7 S$ (unknown), we designated the S7-RNase in $S 7$-allele of 'Akane' as the Sd-RNase in $S d$ allele. Because the nucleotide sequence of S7RNase isolated from 'Idared' differed from that in 'Akane', we could not confirm whether or not the first 49 amino acids of the S7-RNase in 'Idared' were exactly the same as those of the Sd-RNase in 'Akane'.

The cloned cDNA inserts of Sd (851 bp) and Sh (840 bp) contain 684 bp (228 amino acids) and $678 \mathrm{bp}$ (226 amino acids) of coding regions, respectively. In apple, S2-, S3-, S9-, Sf-, Sg-, S24-, S26-, and S27-RNase code for polypeptides containing 226-228 amino acids. The termination codon TAA is present at positions 751-753 (Sd) and 679$681(\mathrm{Sh})$, followed by the $3^{\prime}$ untranslated

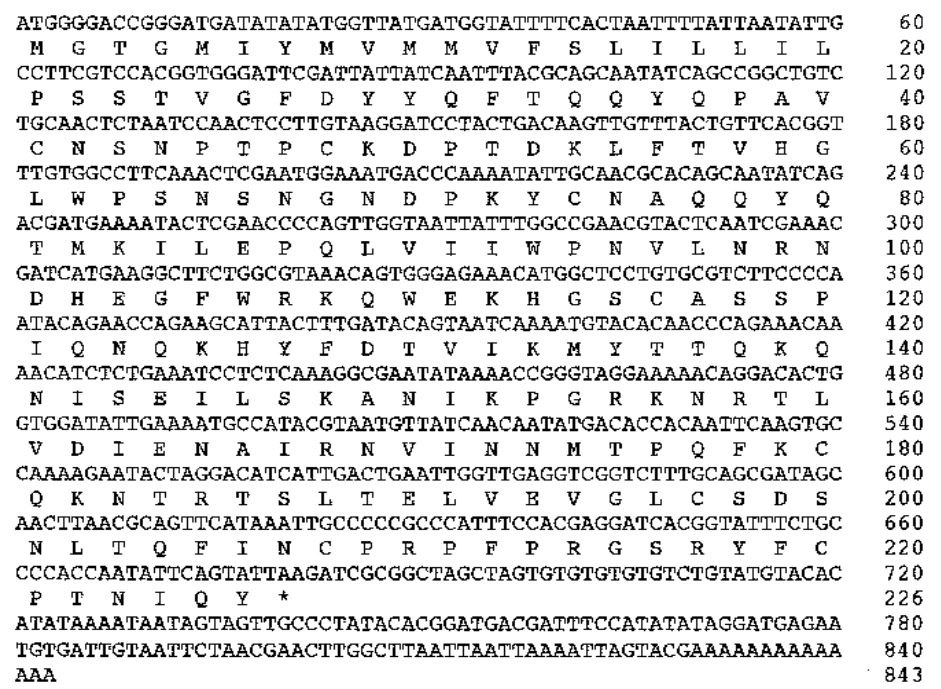

Fig. 1. Nucleotide and deduced amino acid sequences of the Sh-RNase cDNA from 'Akane' apple. The first three nucleotides were from the $3^{\prime}$-nucleotide triplet of the OWB 134 primer. Asterisk indicates stop codon. The sequence of the Sh-RNase cDNA was deposited under the DDBJ accession number AB032247. 
CCACCACCACTTCGATCGATCAAATTAGTAATTAATCTGCCTCGCTCITCGACTAATAT 60 TATTCAATGGGGATTACGGGGATGATATATATGGTTACGATAGTATTTTCATTAATTETT 120

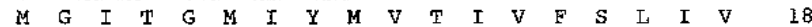
THACTATTGTCTTCGTCCGCGGCGAGATACGATMATHTTCAATTACGCAGCAGTATCAG 180

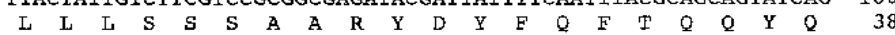
TTGGCTGCCTGCAACTCTAAACCTATTCCTTGTAAGGATCCTCCTGACAAGTTGTTTACG 240

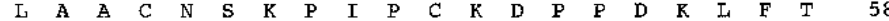
GTTCACGGTTTGTGGCCTTCAGACTCGAATGGACATGACCCAGTAAATRCCAGTAAATCA 300 $\begin{array}{llllllllllllllllllllll}V & H & G & L & W & S & D & S & N & G & D & P & V & N & C & S & K & S & 78\end{array}$ ACCGTGGATGCTCAGAAGTTAGGAAATCTGACAACTCAGTTGGAAATAATTTGGCCGAAC 360

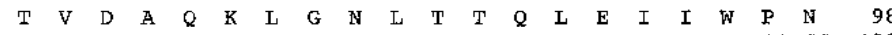
GTATACAATCGAACCGATCATATAAGCTTCIGGGATAAACAGTGGAACAAACATGGCACC 420 $\begin{array}{lllllllllllllllllllll}V & \mathrm{H} & \mathrm{N} & \mathrm{R} & \mathrm{T} & \mathrm{D} & \mathrm{H} & \mathrm{I} & \mathrm{S} & \mathrm{F} & \mathrm{W} & \mathrm{D} & \mathrm{K} & \mathrm{Q} & \mathrm{W} & \mathrm{N} & \mathrm{R} & \mathrm{H} & \mathrm{G} & \mathrm{T} & 118\end{array}$ TGTGGACATCCCACAATAATGAACGACATHCATMACTITCAAACAGTAATCAAAATGTAC 480 $\begin{array}{llllllllllllllllllllll}C & G & B & P & T & I & M & N & D & I & H & Y & F & Q & T & V & I & K & M & Y & & 138\end{array}$ ATARCCCAGAAACAAARCGTCTCTAAAATCCTCTCAAGGGCGAAGATTGAACCGGAGGGG 540 $\begin{array}{lllllllllllllllllllll}I & T & Q & K & Q & N & V & S & K & I & L & S & R & A & R & I & B & P & B & G & 158\end{array}$ AAACCCAGGAAACAGGTAGATATTGTAAATGCCATACGCAAAGGTACAAACGATAAGGAA 600

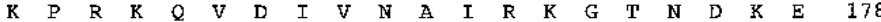
CCAAAACTCAAGHGCCAAAAGAATAACCAGGTGACTGAATTGGTTGAGGTCACTCTITTEC 660

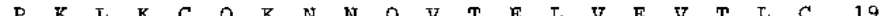
AGTAATCGCAACCTAACGGGGTTCATAAATTGCCCCCGCCATATTCCAAATGGATCACGA 72 $\begin{array}{llllllllllllllllllllll}S & N & R & I & I & T & G & F & I & N & C & P & R & H & I & P & N & G & S & R & 218\end{array}$ TATTCCTGCCCCACCAAAAATATTCTGTATTAAGAGCGCTGCTAGCTATATATATAGACG 780 $\begin{array}{lllllllllllll}Y & S & C & P & T & K & N & I & I & Y & * & 228\end{array}$ GGTGACCATTTCCATATAATGAATAACTTGGCTTAATTAATTAAACTCATGTGAATATGA 840 ADAAAAAAAAA

Fig. 2. Nucleotide and deduced amino acid sequences of the Sd-RNase cDNA from 'Akane' apple. Asterisk indicates stop codon. The sequence of the Sd-RNase cDNA was deposited under the DDBJ accession number AB032246.

Table 1. $S$-allele genotypes of apple cultivars.

\begin{tabular}{lcc}
\hline Cultivars & Parentage & $S$-allele genotypes \\
\hline Akane & Jonathan x Worcester Pearmain & $S d S h$ \\
Akibae & Senshu x Tsugaru & $S 3 S f$ \\
Ambitious & Toukou x ? $^{\mathrm{z}}$ & $S 2 S 9$ \\
Benihazuki & Tsugaru x ? & $S 2 S 3$ \\
Chouka 8 & Akane x Tsugaru & $S 3 S d$ \\
Chouka 17 & Golden Delicious x Senshu & $S 2 S d$ \\
Cox's Orange Pippin & & $S 5 S 9$ \\
Hac 9 & Fuji x Tsugaru & $S 3 S 9 S f$ \\
Homei & mutant of Tsugaru & $S 3 S d$ \\
Kidd's Orange Red & & $S 5 S 9$ \\
Michinoku & Kitakami x Tsugaru \\
Natsumidori & Kitakami x Meku 10 & $S 3 S 9$ \\
North Queen & Fuji x Tsugaru & $S 3 S 9$ \\
Shinsekai & Fuji x Akagi & $S 3 S f$ \\
Worcester Pearmain & & $S 3 S f$ \\
Yataka & sport of Fuji & $S 2 S h$ \\
\hline
\end{tabular}

z?Pollen parent is unknown. region. The deduced amino acid sequence of Sh-RNase showed a high similarity to both Sf- $(92.5 \%)$ and Sg-RNase (93.4\%). The similarities ranged from $92.5 \%$ to $93.8 \%$ among Sf-, Sg-, and Sh-RNase, and from $57.0 \%$ to $73.7 \%$ for S2-, S3-, S5-, Sd-, S9-, S26-, and S27-RNase.

We identified the $S 2-, S 3-, S 5-, S d-$ (=S7-), S9-, and $S f$-alleles of 'Akane', 'Akibae', 'Ambitious', 'Benihazuki', 'Chouka 8', 'Chouka 17', 'Cox's Orange Pippin', 'Hac 9', 'Homei', 'Kidd's Orange Red', 'Michinoku', 'Natsumidori', 'North Queen', 'Shinsekai',

'Worcester Pearmain', and 'Yataka' using the $S$-allele specific PCR-RFLP analysis method described by Matsumoto et al. (1999a, 1999b) (Table 1). These cultivars are commercially less important than those examined by Sakurai et al. (1997) and Matsumoto et al. (1999a, 1999b). However, as these cultivars might be parents of new cultivars in the future, knowledge of their $S$-genotypes may be useful in selecting compatible parents in a breeding program.

Although the method of $S 24$-allele specific PCR analysis was developed by Verdoodt et al. (1998), the method cannot distinguish $S 24$ from $S f$ and $S g$. From the sequence data of SfRNase of 'Fuji' (Sassa et al., 1996), Sg-RNase of 'Indo' (Kitahara et al., 1999) and Sh-RNase of 'Akane' (this paper), we developed a method to distinguish $S h$ - (= S24) from $S f$ - and $S g$ alleles using restriction enzyme analyses. A 370-bp genomic fragment was obtained from 'Indo', of which the $S$-genotype was $S 7 S g$ (Matsumoto etal., 1999a), 'Iwakami', of which the $S$-genotype was S7Sf (Matsumoto et al., $1999 b$ ) and from 'Akane', using the $S f$-, $S g$ and $S h$-allele-specific primers, $S f$-sense 3 and Sf-antisense 2 (Fig. 3). No fragment was obtained from 'Golden Delicious', of which the S-genotype was S2S3 (Janssens et al., 1995), 'Kidd's Orange Red' (S5S9), 'Chouka 8' (S3S7), or 'Baskatong', of which the $S$ -

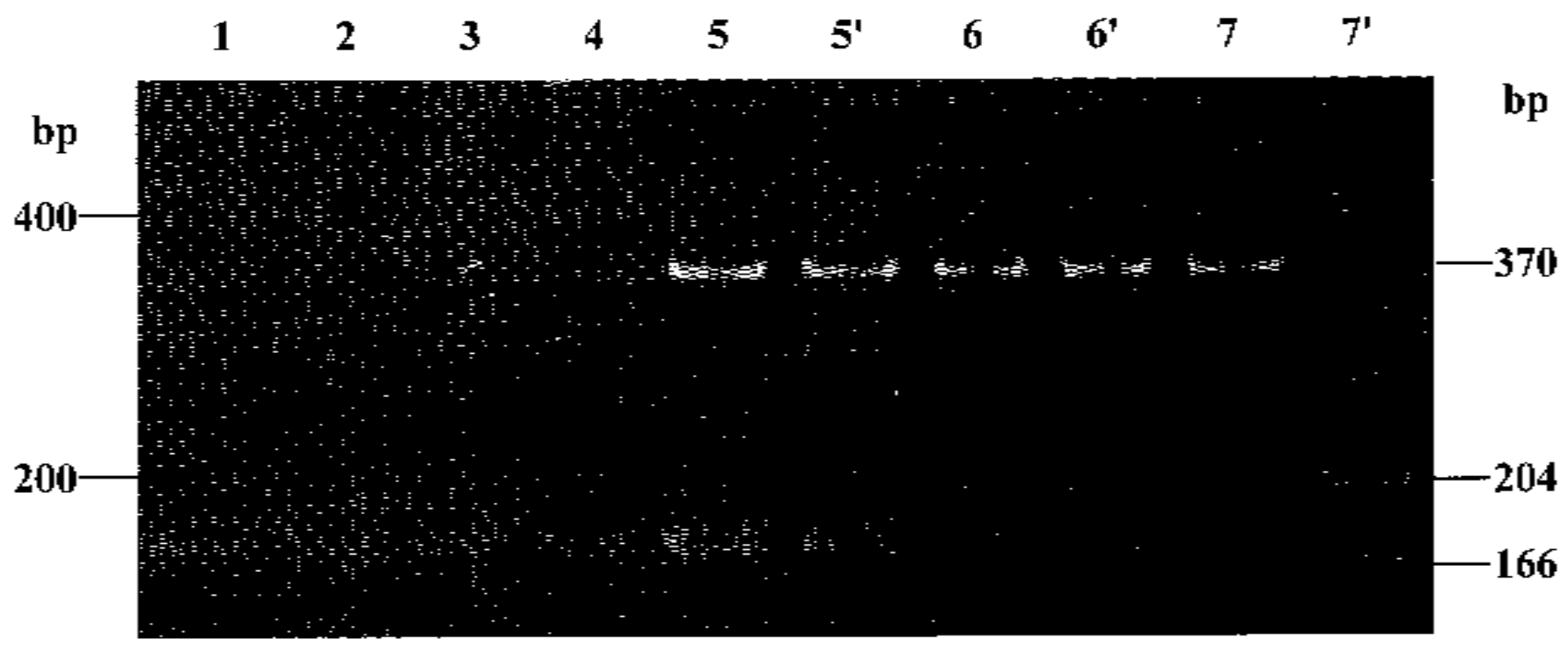

Fig. 3. Sh-allele specific PCR-RFLP analysis. PCR products obtained by using 'Golden Delicious' (S2S3) (lane 1), 'Kidd's Orange Red' (S5S9) (lane 2), 'Chouka 8' (S3S7) (lane 3), 'Baskatong' (S26S27) (lane 4), 'Indo' ( $S 7 S g$ ) (lane 5, 5'), 'Iwakami' (S7Sf) (lane 6, 6'), and 'Akane' (SdSh) (lane 7, 7') genomic DNA as templates, and Sf-sense 3 and Sf-antisense 2 primer. The products were digested by SnaBI (lane $5^{\prime}, 6^{\prime}, 7^{\prime}$ ). 
genotype was $S 26 S 27$ (Verdoodt et al., 1998)

(Fig. 3). By SnaBI digestion, the 370-bp genomic fragment of 'Akane' $(S h)$ was separated into 204-bp and 166-bp fragments, while the fragments of 'Iwakami' $(S f)$ and 'Indo' $(\mathrm{Sg})$ were not (Fig. 3). Using this method, the $S h$-allele in 'Worcester Pearmain' was identified (Table 1). The $S h$-allele was also present in 'Vista Bella' and 'Tohoku 2' ('McIntosh' $x$ 'Worcester Pearmain').

Previously, we developed a method to distinguish the $S f$ - and $S g$-allele by PCR-RFLP (Matsumoto et al., 1999a). In this method, the $1047 \mathrm{bp}(S f)$ or $1021 \mathrm{bp}(S g)$ of amplified fragments obtained by using Sf-sense 2 and Sf-antisense 2 primers were digested by $R s a \mathrm{I}$ or Sau3AI, then each allele was identified by specific fragments for the $S f$ - or $S g$-allele (Matsumoto et al., 1999a). Although about a 1040-bp genomic fragment was obtained from Sh using the primers Sf-sense 2 and Sf-antisense 2, neither the 337-bp fragment specific for $S f$ nor the 122-bp and the 78-bp fragments specific for $S g$ obtained by $R s a$ I digestion (Matsumoto et al., 1999a) were detected from $S h$ (data not shown). This result indicates that the method to distinguish between the $S f$ - and $\mathrm{Sg}$-allele could be useful for identifying those alleles within $S f S h$ or $S g S h$ genotypes. The cDNA sequences of the S-RNases in the $S e$ allele and in 'McIntosh' ( $S$-allele genotype unknown) are under investigation.

\section{Literature Cited}

Broothaerts, W., G.A. Janssens, P. Proost, and W.F. Broekaert. 1995. cDNA cloning and molecular analysis of two self-incompatibility alleles from apple. Plant Mol. Biol. 27:499-511.

Chang, S., J. Puryear, and J. Cairney. 1993. A simple and efficient method for isolating RNA from pine trees. Plant Mol. Biol. Rpt. 11:113-116.

Frohman, M.A., M.K. Dush, and G.R. Martin. 1988. Rapid production of full-length cDNAs from rare transcripts: amplification using a single gene-specific oligonucleotide primer. Proc. Natl. Acad. Sci. USA 85:8998-9002.

Janssens, G.A., I.J. Goderis, W.F. Broekaert, and W. Broothaerts. 1995. A molecular method for $S$-allele identification in apple based on allele-specific PCR. Theor. Appl. Genet. 91:691698.

Kitahara, K., H. Fukui, J. Soejima, and S. Matsumoto. 1999. Cloning and sequencing of a new $S$-gene 'Sg-RNase' (Accession No. AB019184) from Malus $\times$ domestica Borkh. 'Indo'. (PGR99-046) Plant Physiol. 119:1567.

Komori, S., J. Soejima, Y. Ito, H. Bessho, K. Abe, and N. Kotoda. 1998. Analyses of the selfincompatibility genotypes in some apple cultivars (in Japanese). J. Jpn. Soc. Hort. Sci. 67:917926

Matsumoto, S., K. Kitahara, S. Komori, and J. Soejima. 1999a. A new $S$-allele in apple ' $S g$ ', and its similarity to the ' $S f$ ' allele from Fuji. HortScience 34:708-710.

Matsumoto, S., S. Komori, K. Kitahara, S. Imazu, and J. Soejima. 1999b. S-genotypes of 15 apple cultivars and self-compatibility of 'Megumi'. J. Jpn. Soc. Hort. Sci. 68:236-241.

Sakurai, K., S. K. Brown, and N. F. Weeden. 1997. Determining the self-incompatibility alleles of Japanese apple cultivars. HortScience 32:12581259.

Sassa, H., T. Nishio, Y. Kowyama, H. Hirano, T. Koba, and H. Ikehashi. 1996. Self-incompatibility $(S)$ alleles of the Rosaceae encode members of a distinct class of the T2/S ribonuclease superfamily. Mol. Gen. Genet. 250:547-557.

Thomas, M., S. Matsumoto, P. Cain, and N.S. Scott. 1993. Repetitive DNA of grapevine: Class present and sequences suitable for cultivar identification. Theor. Appl. Genet. 86:173-180.

Verdoodt, L., A. Van Haute, I.J. Goderis, K. De Witte, J. Keulemans, and W. Broothaerts. 1998. Use of the multi-allelic self-incompatibility gene in apple to assess homozygocity in shoots obtained through haploid induction. Theor. Appl. Genet. 96:294-300. 